\title{
ATENDIMENTO INTEGRAL À SAÚDE DO IDOSO RESIDENTE EM INSTITUIÇÃO DE LONGA PERMANÊNCIA: uma experiência interdisciplinar
}

\author{
Gislaine Cristina Vagetti* \\ Marlei Salete Weinheimer ${ }^{* *}$ \\ Valdomiro de Oliveira ${ }^{* * *}$
}

\section{Resumo}

A população idosa residente em instituições de longa permanência, conveniadas ao Ministério do Desenvolvimento Social e Combate à Fome (MDS), é de 24.964 idosos (CAMARANO, 2004). O cuidado ao idoso, nestas instituições, requer atenção integral e ações interdisciplinares, portanto o objetivo deste projeto é desenvolver o conhecimento e a prática geriátrica e gerontológica a partir de um modelo biopsicossocial. Sua implantação se deu em uma Instituição de Longa Permanência (ILP) de caráter filantrópico que atende 63 idosos de ambos os sexos, com idade entre 60 a 92 anos, sendo $30 \%$ portadores de déficit na capacidade funcional. As atitudes desenvolvidas incluem atendimento psicológico, exercícios físicos, cuidados de enfermagem, lazer, atenção odontológica e atenção farmacêutica. Além da prática profissional desenvolvem-se pesquisas interdisciplinares entre os profissionais e os acadêmicos. Os resultados mostraram que, a partir de uma abordagem biopsicossocial, os idosos obtiveram melhoras na capacidade funcional, recuperação da integridade cutâneo-mucosa, menor índice de desidratação e desnutrição, diminuição de conflitos pessoais e diminuição do índice de sintomas depressivos. Diante do exposto conclui-se que a Instituição para idosos cumpre uma importante função social junto aos idosos carentes, abandonados que não conseguem sobreviver com recursos próprios. Contudo a perda de identidade e independência são ameaças constantes. A implantação de um projeto de atenção integral

\footnotetext{
Mestre em Ciências da Saúde e Professora do Curso de Educação Física do Centro Universitário de Maringá (CESUMAR). E-mail: gislaine@cesumar.br

** Licenciada em Educação Física. E-mail: marwinh@ig.com.br

*** Doutorando em Ciências do Esporte pela Universidade Estadual de Campinas (UNICAMP).

E-mail: oliveira@pedagogiadobasquete.com.br
} 
às necessidades do idoso possibilita a garantia de uma maior qualidade de vida a partir de ações pautadas no método científico, na ética e no humanismo.

Palavras-chave: Instituições de Longa Permanência. Idoso e Modelo Biopsicossocial.

\section{Introdução}

Segundo o relatório V Caravana Nacional de Direitos Humanos: uma amostra da realidade dos abrigos e asilos de idosos no Brasil, publicado pela Comissão de Direitos Humanos da Câmara dos Deputados (BRASIL, 2002), o número de idosos residentes em Instituições de Longa Permanência (ILPs), era de 19 mil em todo o país. Por outro lado, dados da Gerência de Atenção à Pessoa Idosa do Ministério do Desenvolvimento Social e Combate à Fome (MDS) mostram que o total de idosos que se utilizam das ILPs, conveniadas ao Ministério, até o ano 2004, eram de 24.964 idosos (CAMARANO, 2004). É sabido que a institucionalização é o último recurso que se busca para o atendimento sócio-sanitário para o idoso. Sabe-se também, que a questão da assistência para idosos em instituições como estas, são de altos custos e grandes dificuldades de manutenção.

No caso do Brasil, a grande maioria das ILPs é filantrópica e conta com apoio de congregações religiosas da comunidade e dos próprios idosos que contribuem com grande parte da sua aposentadoria. Desta forma, as instituições encontram-se com poucos recursos, principalmente com relação a pessoal qualificado/capacitado para o cuidado adequado às necessidades biopsicossociais desta parcela da população.

O cuidado é uma das essências que integra e estrutura o ser humano. Como tal, é imprescindível na promoção da vida, da saúde e manutenção da espécie.

Numa perspectiva mais abrangente de cuidado à saúde, Weil (2000) afirma que não é só a pessoa que tem de ser saudável, mas também o grupo ou a sociedade em que ela vive. A saúde ultrapassa, conseqüentemente, o domínio do indivíduo. Assim devemos levar em consideração o homem, a sociedade e a natureza para chegarmos a uma 
definição mais acertada da saúde, implicando a interdependência dos três. De acordo com o mesmo autor:

Uma sociedade saudável se caracteriza por uma cultura dos altos valores da humanidade, tais como beleza, a verdade, a justiça, a liberdade, a igualdade, a fraternidade, entre outros. No plano da vida social e político, teríamos predomínio da cooperação, sinergia. A economia seria caracterizada pelo conforto essencial, Isto é, comida saudável, abrigo, roupa e possibilidade financeira de evoluir. (WEIL, 2000, p. 41).

A abordagem científica tem procurado, ao longo do tempo, aprimorar cada vez mais a qualidade do "cuidar", buscando sempre integrar em sua configuração técnico-científica a dimensão humanista como essência que constitui a natureza humana. Desta forma, os termos multidisciplinar (que envolve várias disciplinas) e interdisciplinar (que estabelece relações entre dois ou mais ramos do conhecimento), ambos conceituados pelo Dicionário Houaiss da Língua Portuguesa (HOUAISS; VILLAR, 2004), utilizados aqui, referem-se à área do conhecimento que visa compreender o homem de forma integral no contexto de sua experiência, vivenciada em cada ciclo de seu desenvolvimento. No caso da população idosa, o cuidado às necessidades de saúde requer o desenvolvimento de um corpo de conhecimento multidisciplinar através de práticas de assistência e de pesquisa em seus diversos contextos de vida.

O projeto em desenvolvimento, refere-se a um processo educativo, cultural e científico que articula o ensino, a pesquisa e a assistência de modo indissociável. Tem como objetivo, desenvolver o conhecimento e a prática geriátrica e gerontológica, utilizando uma metodologia interdisciplinar a partir da concepção holística de saúde, visando o atendimento integral às necessidades de saúde dos idosos residentes em uma ILP de uma cidade do Sul do Brasil.

Esta experiência, envolvendo docentes e discentes de duas Universidades e técnicos da própria ILP, tem favorecido a compreensão da realidade humana em sua multidimencionalidade e permitido o desenvolvimento de uma prática de saúde com perspectivas holísticas. 


\section{Revisão de Literatura}

O mundo tem vivido nas últimas décadas uma transição demográfica e epidemiológica sem precedentes na história da civilização humana. O Brasil se destaca neste cenário como um dos países em desenvolvimento onde a população idosa mais cresce. A projeção que se faz do número de idosos com idade igual ou superior a 60 anos para 2025 é de mais de 30 milhões, atingindo o sexto lugar no ranking mundial.

A velhice é um período em que, não morrendo prematuramente, todos terão de vivenciá-la. A duração dessa fase, não sabemos. Precisamos nos preparar para atender essa parcela da população.

As causas do envelhecimento humano ainda permanecem relativamente obscuras. Alguns especialistas descrevem que tais causas podem ter suas origens tanto nas forças externas quanto nas internas, respondendo estas pelas alterações fisiológicas, ocorrendo nas funções e formas dos órgãos internos e as externas são referentes ao meio ambiente influenciando sobre o organismo humano quer por razões sociais, culturais e econômicas (ZIMERMAM, 2000).

Muitos cientistas, quando falam em envelhecimento, preocupam-se apenas com a parte física e esquecem dos aspectos cognitivos, motivacionais, sociais, entre outros. Para nós, a preocupação com a velhice e a pessoa idosa transcende à dimensão biológica. Implica buscar incessantemente uma perspectiva positiva da idade madura que inclui, entre outras ações, realizar exercícios freqüentes e interessar-se pela atividade cerebral, fonte de uma vida criativa e de plena satisfação como forma de retardar os efeitos deletérios do envelhecimento, ou seja, trabalhar com o idoso de forma integral.

Alguns efeitos nítidos da idade ocorrem no aprendizado, na memória recente e na resolução de problemas - deficiências cognitivas provavelmente atribuídas à redução progressiva da velocidade de processamento de informações (OKUMA, 1998).

A maioria dos idosos acaba aceitando a diminuição do potencial do cérebro, do impulso sexual e a baixa imunidade às doenças, além da falsa perda da capacidade humana, achando que esses problemas são partes naturais do envelhecimento (ANDRADE, 2003).

$\mathrm{O}$ envelhecimento não precisa ser encarado como o fim e que a 
única coisa que o idoso deve fazer é esperar a morte chegar. Acreditamos que pessoas, mesmo com a idade avançada, podem preservar sua capacidade funcional, principalmente para as tarefas do dia-a-dia.

Parte da população idosa vive em condições degradantes, contradizendo os princípios e objetivos de uma sociedade democrática e defensora da dignidade humana. São muitos os idosos que se encontram em situação de exclusão e marginalidade, sem qualquer valor para a sociedade, sem reconhecimento; e a falsa ilusão, centrada em mitos e estereótipos já pré-concebidos, associa a velhice à doenças e decrepitude, o que produz e reproduz, em grande medida, uma perspectiva negativa desta fase da vida (ANDRADE, 2003).

O envelhecimento populacional acarreta previsíveis conseqüências sociais, culturais e epidemiológicas para os quais os profissionais de saúde e a sociedade em geral devem se preparar para um enfrentamento adequado. Dentro deste cenário, podemos considerar dois aspectos de envelhecimento:

a) o do idoso que apresenta a preservação da independência física e mental e da autonomia, e assim consegue viver sem ajuda para suas atividades diárias;

b) o do idoso fragilizado que demanda cuidados especiais.

Embora a grande maioria da população idosa tenha condições de viver e manter-se sozinha ou com a ajuda de familiares, existe uma parcela cuja demanda de institucionalização cresce cada vez mais. Esta parcela geralmente é constituída por idosos pobres com algum tipo de doença, sem condições de viverem sozinhos ou com seus familiares.

Alguns fatores predispõem idosos a buscarem residência em instituições que atendem a essa população, que de acordo com Kane e Kane (1987) são: a idade, diagnóstico, limitação nas atividades diárias (AVD), moram sozinhos, estado civil, situação mental, etnia, ausência de suportes sociais, pobreza, entre outros. É consenso entre os estudiosos da gerontologia que, para melhorar sua qualidade de vida, o idoso deva permanecer no seio familiar. Entretanto, sabe-se que esta condição não é possível para todos.

Quanto às instituições de longa permanência, o autor supracitado, afirma ser preciso levar em consideração que estas cumprem dupla função: a de ser um lugar para os idosos viverem e a de proporcionar os cuidados que necessitam. 
Born e Boechat (2002), reiteram que a qualidade dos cuidados aos idosos, nestes ambientes, pode recuperar a vontade de viver destas pessoas e a sua saúde, bem como criar novas relações sociais. Mas por outro lado, alertam, que a realidade mostra a maioria das instituições desqualificadas, com estruturas constrangedoras, com critérios padronizados que impossibilitam a expressão individual, despersonalizando o indivíduo e afastando-o do convívio familiar e social.

Segundo Antonio Jordão Netto (1987), as instituições para idosos, surgem como resposta natural da sociedade para atender essas pessoas desprovidas de recursos, ou aquelas cuja família não tem condições de assumir, por problemas de saúde, por falta de condições financeiras e mesmo por falta de investimentos afetivos ou limitação de espaço.

Por outro lado, entendemos que a este conjunto multifatorial da institucionalização do idoso, podemos acrescentar ainda, a própria concepção distorcida que em certa medida permeia a representação social sobre velhice que a define apenas como sendo a última fase da vida. Este fato contribui muito para a segregação da pessoa idosa, não só em ILPs, como também no próprio seio da sociedade.

Não compartilhamos com a idéia de que a velhice seja, simplesmente, a última fase da vida, pois se assim o fosse, não encontraríamos mais motivação para viver, quando adentrássemos neste processo natural, como o da dinâmica do universo.

Segundo Papaléo Netto (2002), o envelhecimento é um processo, que começa desde a concepção da vida e que termina com a morte. Nele observamos fases do desenvolvimento humano como a puberdade e maturidade, considerados marcadores biofisiológicos, sendo a velhice uma das fases desse processo.

Para nós, o processo de envelhecimento é um sucesso tanto individual quanto social, e a velhice, uma nova fase do desenvolvimento humano e como tal, uma oportunidade de grandes realizações. Neste sentido, faz-se necessário o desenvolvimento do saber profissional acerca deste período da vida humana, com objetivos de promover uma melhor qualidade de vida para essa faixa etária. 


\section{Fundamentação Teórica}

Este projeto, dirigido aos idosos residentes em instituições de longa permanência, visa à melhora de sua qualidade de vida, a partir da integração entre comunidade e instituição. Contudo, para se atingir os objetivos propostos, acreditamos que deve estar fundamentado num referencial teórico apropriado. Assim, optamos pela abordagem holística de saúde que compreende fundamentalmente conceitos de concepção sistêmica e transdisciplinaridade. A concepção sistêmica, de acordo com Crema (1989), consiste na consideração de que todos os fenômenos e eventos estão interligados e interrelacionados de forma global, orientando a construção do paradigma holístico atual. Com relação à transdisciplinaridade, o autor explica que o termo transcende o enfoque disciplinar. Neste sentido a multidisciplinaridade e interdisciplinaridade também se fazem necessárias quando o assunto é o holismo. Trata-se de uma evolução qualitativa da consciência que representa a cooperação sinérgica entre os diversos tipos de conhecimento.

Numa abordagem holística, portanto, a realidade não pode ser compartimentalizada de fato. Ela ultrapassa as fronteiras construídas a partir das ilusões da separatividade.

Para Leloup et al. (1997) a palavra holística se origina do termo grego holos, que quer dizer inteiro. Tem como característica essencial o acolhimento de todas as condições do ser humano. Cada vez que fazemos um diagnóstico, devemos considerar as questões físicas, bioquímicas, somáticas, neurofisiológicas, psíquicas, emocionais, mentais e sociais.

O pensamento holístico é profundamente ecológico, considera o homem como parte integrante e inseparável do grande universo uno. Este princípio de totalidade mostra que somos a parte de um todo indivisível. Paradoxalmente somos microcosmos no macrocosmos, pois ao mesmo tempo que estamos contidos no universo, o universo está contido em nós.

A perspectiva de totalidade muda a nossa vida no sentido de incluir em vez de excluir e assim, expande a sensibilidade interior para todo o ser físico, emocional, mental e espiritual, dá à vida o sentido de movimento, de multidimensionalidade (CREMA, 1989). A partir desta visão de mundo, desenvolvemos este projeto, praticando o cuidado à 
saúde dos idosos, baseados em ações interdisciplinares, entendendo o homem como um ser inacabado, inconcluso, e que traz em si o potencial da transcendência, mesmo vivenciando o período da senescência, cujas dimensões biológicas, psicológicas, sociais e espirituais atuam de modo interdependente.

O presente projeto, portanto, é desenvolvido com vistas a atingir a saúde holística. Deste modo requer dos docentes e discentes participantes, a atenção com o autoconhecimento e crescimento pessoal para prover cuidados aos idosos, considerando-os como seres integrais e partes constituintes do contexto em que vivem.

\section{Materiais e Métodos}

O projeto em pauta tem como propósito uma contribuição para o ensino, à pesquisa e à prática de cuidado para com o idoso em uma instituição de longa permanência.

O local de implantação é uma instituição de caráter filantrópico, dirigida por integrantes Vicentinos da Congregação Católica Apostólica Romana. A população atendida é constituída por 63 idosos entre 60 e 92 anos de idade do sexo feminino e masculino com capacidade funcional preservada e/ou com variados graus de dependência. O projeto teve início em junho de 2003, com perspectiva de tornar-se permanente.

Compreendemos o idoso como um ser uno, integral e indivisível; assim, elaboramos uma Sistematização de Assistência Integral à Saúde do Idoso (SAISI).

Medicina, Enfermagem, Psicologia, Farmácia, Fisioterapia, Educação Física,Terapia Ocupacional e Assistência social são as disciplinas envolvidas no projeto, sendo os seus representantes docentes, técnicos e acadêmicos como descrito a seguir: (1) um médico (técnico); (3) três Enfermeiros (docentes); (1) um Educador físico (docente) e (6) seis acadêmicas (Educação Física); (1) uma Psicóloga (docente); (1) uma Farmacêutica (docente), (1) uma acadêmica (Farmácia); (1) um Fisioterapeuta, (1) uma Terapeuta Ocupacional e (1) uma Assistente Social.

As atividades são desenvolvidas duas vezes por semana com uma sistemática interação sinérgica entre os componentes do projeto. Há troca de informações, experiências e apoio mútuo. Desta forma, to- 
das as ações são desenvolvidas de forma integralizada, ou seja, as atividades de cada disciplina se interagem, de maneira que cada membro atuante tenha o conhecimento das ações um do outro.

A SAISI é operacionalizada a partir de um processo organizacional constituído de um prontuário único denominado: Prontuário Geronto-geriátrico.

A dinâmica de funcionamento do Prontuário Geronto-geriátrico (PGG), é desenvolvida de acordo com a necessidade de saúde biopsicossocioespiritual do idoso conforme descrito abaixo:

a) histórico geronto-geriátrico: trata-se da primeira fase da SAISI. Aqui são coletadas e registradas as informações gerais e específicas do idoso sob o enfoque do modelo Biopsicossocioespiritual. Profissionais das diferentes disciplinas registram dados/informações significativas para posterior análise e definição de diagnósticos;

b) diagnóstico geronto-geriátrico: essa fase da SAISI deriva da avaliação acurada do histórico e busca identificar as necessidades de saúde do idoso. O diagnóstico identificado e registrado orienta o plano de intervenção, ou seja, a prescrição de cuidados profissionais;

c) prescrição de cuidado geronto-geriátrico: esta fase igualmente importante representa a terceira etapa do PGG. Trata-se da descrição expressa, clara e objetiva das ações profissionais específicas, direcionadas às necessidades de saúde integral do idoso. As ações prescritas podem ser implementadas por funcionários da instituição, por acadêmicos das disciplinas já descritas (sob supervisão) e pelos próprios profissionais de nível superior;

d) avaliação do cuidado geronto-geriátrico: esta fase representa a quarta etapa do PGG e refere-se à investigação da eficácia das ações/cuidados implementados. É uma avaliação contínua dos resultados alcançados. Esta avaliação redireciona SAISI a partir da readequação do histórico geronto-geriátrico e todas as outras etapas subseqüentes.

Outrossim, as ações serão balizadas a partir da sinergia em que a colaboração entre os participantes esteja em conformidade com o espírito de equipe. Toda atividade é registrada em impresso. Para melhor desempenho das atividades, uma vez por mês é realizada uma reunião com os participantes para levantamento e discussão de problemas, planejamento e replanejamento de ações. 


\section{Resultados e Discussões Preliminares}

O atendimento integral à saúde do idoso, bem como a avaliação geronto-geriátrica a partir de uma abordagem biopsicossocial, permite constatar uma gama de benefícios, tanto para os idosos institucionalizados como para os participantes do projeto.

No que se refere à dimensão biológica, verificamos melhorias no funcionamento do aparelho músculo-esquelético, propiciando mais agilidade e mais tempo de movimentação entre os idosos. Esta mudança contribuiu com efeitos importantes na saúde integral do idoso, pois conserva o ótimo funcionamento dos sistemas orgânicos.

Com a implementação de cuidados gerontológicos da hidratação, alimentação, movimentação e comunicação, pode ser observado redução importante nas necessidades de consultas médicas e internamento hospitalar.

A mudança na rotina de tratamento de feridas de uma vez para duas vezes ao dia, bem como o uso de produtos alternativos nas lesões, tem contribuído significativamente para o processo de cura de feridas.

Com relação à dimensão psicofísica, podemos verificar que entre os idosos que participam das atividades físicas coletivas e das excursões de lazer (passeios, almoços, pescarias, entre outras) a saúde mental tem melhorado. Este fato pode ser comprovado, a partir de investigação dirigida por participantes do projeto, sobre os graus de sintomas depressivos entre os idosos da instituição.

A presença de acadêmicos, de modo constante na instituição, intensifica qualitativa e quantitativamente, o nível de comunicação social, o que tem contribuído na satisfação das carências afetivas tão presentes nos idosos. Assim, observamos que os idosos apresentam-se menos melancólicos, mais dispostos e comunicativos.

Diante desses resultados, é possível verificar mudanças de comportamento, o que nos remete para uma avaliação positiva da dimensão social entre os idosos. A qualidade das relações interpessoais e o nível de cooperação entre eles têm melhorado em grande medida. Verificamos diminuição dos conflitos pessoais que decorriam da inatividade, segregação, perda de autonomia, de independência e baixa auto-estima.

Se por um lado constatamos, formal (por meio de diversas pesquisas relacionadas aos aspectos físico, mental e social dos idosos) e 
informalmente benefícios advindos do projeto para os idosos, por outro, percebemos também, os benefícios relacionados ao conhecimento do idoso, que o mesmo proporciona aos acadêmicos, profissionais ou docentes de diversas áreas e para os funcionários da instituição que colaboram na realização do projeto. Neste sentido, o exercício interdisciplinar tem contribuído para o crescimento, tanto profissional como pessoal, de todos os envolvidos. O desenvolvimento de ações práticas e de pesquisa tem proporcionado a produção de conhecimento sobre o processo do envelhecimento, a velhice e a pessoa idosa.

\section{Considerações Finais}

Ao finalizar o relato do presente projeto, nos remetemos ao objetivo proposto e aos resultados obtidos.

O desenvolvimento de ações interdisciplinares de atenção integral à saúde do idoso propiciou a percepção do idoso como ser biopsicossocioespiritual. Esta percepção por seu termo, enquadra a integração entre diferentes conhecimentos e conseqüentemente o sinergismo entre as ações de saúde.

Os resultados permitiram concluir que a abordagem biopsicossocioespiritual é a mais adequada para o idoso que vivencia o cotidiano em ILPs. A dimensão biológica não pode ser considerada sem a relação interdependente com a psicológica, a social e a espiritual. Esta via de mão dupla entre as dimensões humanas está congruente com uma concepção de saúde holística que, em síntese, significa o bem estar do idoso, um equilíbrio harmônico entre seu meio interno e o externo.

Se por um lado houve melhoria do bem estar do idoso e uma relação mais positiva com o seu meio, por outro lado, a equipe tem desenvolvido conhecimento na área do envelhecimento, traduzindo-se em crescimento profissional.

Além disso, a experiência de relacionar-se com aqueles que vivenciam o asilamento, tem proporcionado desenvolvimento pessoal, que não pode ser desconsiderado quando pensamos na formação de profissionais que atuam no cuidado à saúde .

A partir dos resultados do projeto, recomenda-se a implantação de práticas assistenciais e pesquisas interdisciplinares voltadas para as pessoas idosas que vivem em instituições de longa permanência. 


\title{
INTEGRAL SERVICE TO INSTITUTIONALIZED SENIOR'S HEALTH: an interdisciplinary experience
}

\begin{abstract}
The resident senior population in institutions of long permanence in Brazil is 24.964. The care to the elderly, in these institutions, requests integral attention and interdisciplinary actions. Therefore, the purpose of this project is developing a geriatric and gerontological practice and knowledge, starting from a biopsychosocial model. Its implantation takes place in a philanthropic long-permanence institution that assists 63 senior of both sexes, from 60 to 92 years old, which 30\% has a deficit in their functional capacity. The developed attitudes include psychological service, physical exercise, nursing cares, leisure, and deontological and pharmaceutical attention. Besides the professional practice, interdisciplinary research was developed among the professionals and academics. The results depicted that when treated by a biopsychosocial approach, the seniors reached improvements in the functional capacity, showed recovery of their cutaneous-mucous integrity membrane, presented lower dehydration index and malnutrition, decrease of personal conflicts and less occurrence of depressive symptoms. As a conclusion, we can state that the Elderly Institution accomplishes an important social function with the disfavored, abandoned seniors, who cannot afford their own surveillance. However, loss of identity and independence are constant threats. The implantation of an integral attention project to the senior's needs can guarantee a better life quality, following a scientific method, the ethics and the humanism.
\end{abstract}

Keywords: Long-Permanence Institutions. Senior and Biopsychosocial Model. 


\section{REFERÊNCIAS}

ANDRADE, Oseias Guimarães. Representações Sociais de Saúde e de Doença na Velhice. Revista Acta Scientiarum. Health Sciences, Maringá, v. 25, n. 2, p. 207-213, 2003.

BORN, Tomiko; BOECHAT, Norberto S. A Qualidade dos Cuidados ao Idoso Institucionalizado. In: FREITAS, Elizabete Viana de et al. (Org.). Tratado de Geriatria e Gerontologia. Rio de Janeiro: Guanabara Koogan, 2002. P. 768-777.

BRASIL. Câmara dos Deputados. Comissão de Direitos Humanos. V Caravana Nacional de Direitos Humanos: uma amostra da realidade dos abrigos e asilos de idosos no Brasil. Brasília, DF: Comissão de Direitos Humanos, 2002. Disponível em: <http://www.dhnet.org.br/dados/caravanas/br/v_caravana.htm>. Acesso em: 08 fev. 2007.

CAMARANO, Ana Amélia. Os Novos Idosos Brasileiros: muito além dos 60 ? Rio de Janeiro: IPEA, 2004.

CREMA, Roberto. Introdução à Mão Holística: breve relato de viagem do velho ao novo paradigma. São Paulo: Summus, 1989.

HOUAISS, Antônio; VILLAR, Mauro de Salles. Dicionário Houaiss da Língua Portuguesa. Rio de Janeiro: Objetiva, 2004.

KANE. Rosalie A.; KANE, Robert L. Long-Term Care: principles. Programs and policies. New York: Springer, 1987.

LELOUP, Jean-Yves et al. Espírito na Saúde. Petrópolis: Vozes, 1997.

NETTO, Antonio Jordão. Asilo de Velhos: uma instituição nada exemplar. Revista São Paulo em Perspectiva, São Paulo, v. 1, n. 3, p. 71-76, 1987.

NETTO, Matheus Papaléo. O Estudo da Velhice no Século XX: histórico, definição do campo e termos básicos. In: FREITAS, Elizabete Viana de et al. Tratado de Geriatria e Gerontologia. Rio de Janeiro: Guanabara Koogan, 2002. P. 2-12. 
OKUMA, Silene Sumire. O Idoso e a Atividade Física. Campinas: Papirus, 1998.

WEIL, Pierre. A Mudança de Sentido e o Sentido da Mudança. Rio de Janeiro: Record: Rosa dos Tempos, 2000.

ZIMERMAM, Guite I. Velhice: aspectos biopsicossociais. Porto Alegre: Artmed, 2000 .

Recebido: 09.12.2005

$1^{a}$ revisão: 30.08 .2006

$2^{a}$ revisão: 31.01 .2007

$3^{a}$ revisão: 24.07 .2007

Aceite final: 01.08.2007 